\title{
Tangence
}

Rachel Leclerc, Rabatteurs d'étoiles, Montréal, Le Noroît, 1994.

\section{Jaqueline Chénard}

Numéro 46, décembre 1994

Un théâtre de passage

URI : https://id.erudit.org/iderudit/025844ar

DOI : https://doi.org/10.7202/025844ar

Aller au sommaire du numéro

Éditeur(s)

Tangence

ISSN

0226-9554 (imprimé)

1710-0305 (numérique)

Découvrir la revue

Citer ce compte rendu

Chénard, J. (1994). Compte rendu de [Rachel Leclerc, Rabatteurs d'étoiles,

Montréal, Le Noroît, 1994.] Tangence, (46), 101-105.

https://doi.org/10.7202/025844ar

Ce document est protégé par la loi sur le droit d'auteur. L'utilisation des services d'Érudit (y compris la reproduction) est assujettie à sa politique d'utilisation que vous pouvez consulter en ligne.

https://apropos.erudit.org/fr/usagers/politique-dutilisation/
Cet article est diffusé et préservé par Érudit.

Érudit est un consortium interuniversitaire sans but lucratif composé de l’Université de Montréal, l'Université Laval et l'Université du Québec à Montréal. Il a pour mission la promotion et la valorisation de la recherche. https://www.erudit.org/fr/ 


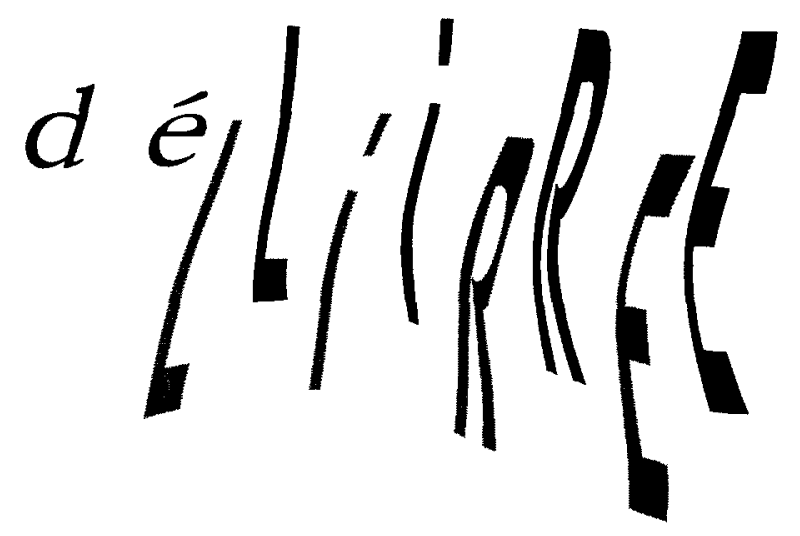

\section{Rachel Leclerc, Rabatteurs d'étoiles, Mont- réal, Le Noroît, 1994.}

L'éditeur nous dit, en quatrième de couverture, que Rachel Leclerc poursuit dans Rabatteurs d'étoiles le "poème des origines" commencé dans son ouvrage précédent, Les vies frontalières, publié en 1991. Il semble qu'ici, pour accéder à la vérité des rapports à l'origine et à leur vie propre,les orphelins frère et sœur du premier poème, dans leur nudité lumineuse, dussent aller jusqu'à trahir l'ancêtre et tuer la demeure (p. 13).

La première partie du recueil, "Le sacrifice", peint le tableau d'un désenchantement :

Cela m'accable si fort

le refus de la vie à se recomposer:

il a neigé cette nuit du vingt-trois avril

quartier vétuste cerné de moiteur glaciale

c'est l'abdication de la moindre beauté (p. 16).

Les fils, engagés dans la lutte perdue d'avance contre l'hiver, disposent d'une liberté dérisoire, voire mortelle:

La saison les retrouve livides et pathétiques

ces fils demeurés dans la maison du père

affectés à la restauration du printemps (p. 14),

Des orphelins oisifs emplissent la ruelle

revenus habiter leur tranchée solitaire

[...] ils ont la liberté définitive et encombrante

des grands vieillards qui s'éloignent dans le ciel

en faisant un bruit de soie chiffonnée (p. 15). 
La fille, la sœur, appelle à la reconnaissance mutuelle des hommes et des femmes, à la solidarité des enfants sacrifiés:

peut-être verras-tu

cette partie de moi qui te reste étrangère

la patience des femmes parmi les pierres

ne ferme pas les yeux sur le massacre

toi aussi tu es le fils qu'on éreinte

tu es le pâle rescapé de la démence

regarde tes sours et apprends:

toutes barricadées sous le territoire

elles sont devenues plages de galets

ou sentier de prêles

[...] ne vois-tu pas ce qui se meurt (p. 18).

Il faut rompre la chaîne de la mort silencieuse, dit la fille, parce que

ce qui meurt emporte avec lui

dans un absolu dérèglement des alliances

sa convoitise et sa plainte

sa déconvenue

ce qui meurt n'a pas grand-chose

à se mettre sous la dent

que la mémoire de ses fils

inutile offrande (p. 19),

dût-on affronter les spectres courroucés des ancêtres :

Tous mes gris-gris lâchés sur le vent

[...] j'attendrai comme un mât totémique

le défilé des ombres au-dessus de ma tête

le tournoiement des spectres sur le littoral

ah! qu'ils viennent tous qu'ils viennent donc

se haïr en moi qu'ils viennent vociférer

sur mes épaules et capituler dans ma voix

[...] pour que le temps m'appartienne j'attendrai

qu'ils viennent s'anéantir une dernière fois (p. 20).

On aura reconnu un rythme à la Michel Beaulieu dans ces multiples enjambements, cette poussée en avant de la phrase qui ajoute à la véhémence du texte. Rachel Leclerc ressent cette parenté avec la poésie de Beaulieu, puisqu'elle lui dédie son recueil. On aura peut-être entendu une note rimbaldienne dans l'absolu dérèglement des alliances. Parsemés dans le texte, brillent des petits éclats des Illuminations et des Poésies de Rimbaud: dans Rabatteurs d'étoiles: 
à l'aube en croisant les hommes

qui soulevaient la poussière de chaux

et rentraient à l'ouvrage (p. 57).

Dans Rimbaud:

À quatre heures du matin, l'été,

[...] En bras de chemise, les charpentiers

déja s'agitent.

Dans Leclerc le "grenier obscur" (p. 55) de l'enfance, et dans Rimbaud ("Vies III", Illuminations) : "un grenier où je fus enfermé à douze ans".

Dans Leclerc:

Les fumées de l'usine là-bas

comme des robes qui montent au ciel (p. 35);

dans Rimbaud ("Ouvriers", Illuminations) : "La ville, avec sa fumée et ses bruits de métiers". Le monde des Rabatteurs d'étoiles est peuplé, comme celui de Rimbaud, de spectres de mères mortes qui déambulent parmi les vivants, rempli d'orphelins en quête d'amour: "orphelins du jour dévêtus côte à côte" (Leclerc, p. 13), "dans cet avare pays où nous ne serons jamais que des orphelins fiancés" (Rimbaud).

Dans "Les dieux peuvent venir", sa deuxième partie, Rachel Leclerc questionne les lieux de l'enfance sur une identité perdue, engloutie:

Enfants des falaises on apprenait

la peur des profondeurs marines

on s'y trouve maintenant

avec le nom attaché aux pieds (p. 25).

En un tel pays, l'appartenance se vit comme un combat avec la grandeur écrasante du paysage, dans lequel on cherche ses propres traces, mais dont on doit se détacher pour accéder à l'existence:

On met au jour

les graphies du tertiaire

on arrache à la commune

ce qui lui reste d'aveux à faire

avant d'entrer en collision

avec l'éternité (p. 26);

Être une pierre en cette contrée

dans la disparition du même

et du soi-même 
104

être une pierre

ne pas être du pays (p. 30).

La vertigineuse verticalité du paysage gaspésien est évoquée par tous ces escaliers que l'on monte ou que l'on descend:

Il y a toujours un vieux

qui descend l'escalier de bois

[...] toujours un vieux qui remonte

l'escalier des souvenirs (p. 32):

Pour monter jusqu'aux colonnes d'un arc-en-ciel

dans l'aggravation des pierres

on a pris l'escalier de la forêt (p. 42).

Pour voyager du monde des morts au monde des vivants, la mère de la locutrice du Jardin chinois, la dernière partie du livre, emprunte elle aussi un escalier:

Il te fallait dévaler en catastrophe

ou gravir avec la plus extrême délicatesse

les marches pour passer en silence

et en tremblant du visible à l'invisible (p. 54).

La locutrice - nous pourrions dire l'auteure, puisque Le jardin chinois est dédié à sa mère - s'adresse au spectre de la mère pour accomplir tous les deuils nécessaires à la reconquête de soi. Deuil du père, déboussolé à la mort de la mère et inapte à conduire la maisonnée dont il était auparavant le capitaine (p. 52):

cet insomniaque qu'il faudrait asseoir

à la place de notre père (p. 55).

Le deuil de la maison, vendue à "un autre clan moins tapageur" (p. 59). Et, bien sûr, le deuil de la mère, qui ne vit la liberté que dans la mort :

même pour les plus jeunes d'entre nous

la liberté t'advenait hors la vie (p. 62),

et dont la présence obsédante, même furtive, finit par être ressentie comme maléfique, puisque les enfants continuent de porter le fardeau de ses peines et de "ses gestes courants de la désillusion" (p. 62):

sache au moins cela ma mère

[...] le temps a porté jusqu'ici tes maléfices (p. 63).

À ce spectre désenchanté, qui surgit jusque dans la foule en chaque femme qui lui ressemble un peu, la locutrice demande une réciprocité de reconnaissance: 
mais saurais-tu me reconnaitre en ce visage si tu l'apercevais fragmenté par la foule pour le refaire avec ses ressemblances le laisser partir et vaquer à l'existence (p. 71).

Elle demande que cette reconnaissance ne lui soit pas fatale, qu'on la laisse habiter en paix son monde des vivants :

est-ce que tu saurais

ne pas franchir le seuil ni casser le miroir

ne pas me reconnaître et passer ton chemin (p. 72).

Le lecteur pressentira, avant d'ouvrir le livre, qu'il s'agit là du carnet d'un deuil, à cause de la matité un peu effrayante du noir de la couverture. Le papier texturé émet au toucher "des bruits de soie chiffonnée. contenus dans le texte. Je suis sortie de ce livre éblouie et tremblante: par la virtuosité de son écriture chaque mot pèse son poids de sens et de sincérité absolue, en même temps que de lumineuse poéticité - Rachel Leclerc donne à sentir toutes les fragilités et toutes les forces mobilisées dans le combat pour la liberté du voyage, pour la simple jouissance du don inaltérable de la vie. 